\title{
A INFLUÊNCIA INTERNACIONAL SOBRE A PEDAGOGIA UNIVERSITÁRIA PARA FORMAÇÃO dO PEDAGOGO E SUA CARACTERIZAÇÃO NA MESORREGIÃo LESTE DE MATO GROSSO DO SUL
}

\author{
THE INTERNATIONAL INFLUENCE UNIVERSITY PEDAGOGY FOR THE PEDAGOGUE \\ TRAINING AND ITS CHARACTERIZATION IN THE EASTERN \\ REGION OF MATO GROSSO DO SUL \\ LA INFLUENCIA INTERNACIONAL SOBRE LA PEDAGOGIA UNIVERSITARIA PARA \\ FORMACIÓN DEL PEDAGOGO Y SU CARACTERIZACIÓN EN LA \\ MESOREGIÓN DEL ESTE DE MATO GROSSO DO SUL

\section{Paulo Fioravante Giareta \\ Valdeci Luiz Fontoura dos Santos \\ Juliana Bernardi Petek}

\begin{abstract}
RESUMO: O artigo socializa resultados de pesquisa que indica pela incidência dos organismos internacionais (USAID, Banco Mundial e UNESCO) sobre a legislação educacional brasileira. A investigação se apoia na análise da oferta do Curso de Pedagogia na região Leste do Estado de Mato Grosso do Sul. Responde pelo objetivo de apontar a caracterização político-pedagógica da influência internacional sobre a política de formação de Pedagogos. Metodologicamente, fundamenta-se na análise documental e na técnica da análise de conteúdo. Os dados foram levantados com suporte nas bases oficiais - MEC, INEP e sites das IES pesquisadas. A pesquisa aponta para uma política de interiorização da educação superior, especialmente para a formação em pedagogia, fundamentada nas matrizes de redução de custos, que no contexto pesquisado, responde por forte vinculação da oferta via instituições privadas, centrada na pedagogia do ensino e com predomínio da oferta na modalidade à distância. Conclui-se que a formação do pedagogo está centrada na oferta do setor privado e a partir de uma pedagogia de formação diversificada.
\end{abstract}

PALAVRAS-ChAVE: Organismo internacional. Pedagogia universitária. Formação de professores. Pedagogia.

ABSTRAC: The article socialize search results indicating the incidence of international organizations (USAID, World Bank and UNESCO) about the brazilian educational legislation. The research is based on analysis of the offer of the course of pedagogy in the eastern region of the State of Mato Grosso do Sul. It responds for the purpose of pointing out the political-pedagogical characterization of the international influence on the pedagogical training policy. Methodologically, is based on documentary analysis and the technique of content analysis. The data have been raised with official bases support-MEC, INEP and site of HEIS surveyed. The research points to a policy of internalization of higher education, especially for training in pedagogy, based on arrays of cost reduction, which in the context search for answers by strong binding offer via private institutions, focused on teaching and pedagogy with a predominance of the offer in distance mode. It is concluded that the education of the pedagogue is centered on the private offer of the offer and from a pedagogy of diversified formation.

KEYWORDS: International body. University pedagogy. Training of teachers. Pedagogy.

RESUMEN: El artículo socializa los resultados de una investigación que indica por la incidencia de los organismos internacionales (USAID, Banco Mundial y UNESCO) sobre la legislación educacional brasileña. La

\footnotetext{
${ }^{1}$ Submetido em: 28/03/2018 - Aceito em: 23/04/2018 - Publicado em: 20/11/2018
}

\begin{tabular}{l|l|l|l|l|l|l} 
(C) Rev. Educ. Perspec. & Viçosa, $M G$ & v.9 & n.2 & p.313-329 & maio/ago. 2018 & eISSN 2178-8359 \\
\hline
\end{tabular}


investigación se apoya en el análisis de la oferta del Curso de Pedagogía en la región Leste de la Provincia de Mato Grosso do Sul. El objetivo es exponer la caracterización política y pedagógica de la influencia internacional sobre la política de formación de Licenciados. Metodológicamente, esta investigación está fundamentada en el análisis documental y en la técnica da análisis de contenidos. Los datos fueron obtenidos con aporte en los textos oficiales - MEC, INEP y sitios de las IES pesquisadas. La búsqueda indica una política de interiorización de la educación superior, especialmente para a formación en pedagogía, fundamentada en las matrices de reducción de costos, que en el contexto pesquisado, equivale a varias plazas ofrecidas por las instituciones privadas, centradas en la pedagogía de enseñanza y con predominancia de cursos de educación a distancia. Concluye que la formación del licenciado está centrada en el ofrecimiento privado y por medio de una pedagogía de formación diversificada.

PAlABRAS-ClAVE: Organismo internacional. Pedagogía universitaria. Formación de profesores. Pedagogía.

\section{INTRODUÇÃO}

A política brasileira de formação de professores, no atual contexto educacional, tem ganhado destaque, quer decorrente dos constantes anúncios dos baixos índices alcançados pela educação básica nos sistemas de avaliação, das dificuldades históricas de conquistas que impliquem em valorização da profissão docente, ou ainda, pela própria expectativa idealizada sobre a atuação docente como fonte de desenvolvimento econômico e social por meio do fomento de competências demandadas pelos novos arranjos produtivos e sociais.

Esse contexto, especialmente para a formação de professores, tem precipitado o aprofundamento do olhar dos agentes da política educacional para as iniciativas em curso no contexto internacional. Razão pela qual, a presente pesquisa filiada a um objetivo maior que disciplina a pesquisa articulada ao projeto "Pedagogia Universitária para Formação de Pedagogos e a Qualidade da Educação Básica,", intenciona socializar resultados que apontam para a incidência dos organismos internacionais sobre a legislação educacional brasileira para as políticas de formação de professores e seus desdobramentos práticos na política de formação de Pedagogos na região Leste de Mato Grosso do Sul.

A pesquisa, metodologicamente, responde pela Análise Documental, que para a organização, leitura e interpretação dos dados conta com o auxílio da técnica da Análise de Conteúdo. Para a caracterização proposta em âmbito internacional, para a pedagogia de formação de professores, o estudo foca, centralmente, na análise da Declaração sobre a Conferência Mundial da Educação Superior para o Século XXI de 1998 e do documento preparatório da Conferência, publicado no Brasil, em 1999, com o título de "Política de Mudança e Desenvolvimento no Ensino Superior”.

A leitura sobre a incidência da proposta na política educacional brasileira responde pela análise do marco legal característico do período pós década de 1990. A percepção dos desdobramentos práticos, por sua vez, elege como lócus para o desenvolvimento da pesquisa

\begin{tabular}{l|c|c|c|c|c|c|} 
(C) Rev. Educ. Perspec. & Viçosa, $M G$ & v.9 & n.2 & p.313-329 & maio/ago. 2018 & eISSN 2178-8359 \\
\hline
\end{tabular}


a região Leste do Estado de Mato Grosso do Sul, região administrativa denominada de Bolsão sul-mato-grossense, com base em dados levantados de plataformas oficiais Ministério da Educação (MEC), Instituto Nacional de Estudos e Pesquisas Educacionais Anísio Teixeira (INEP) e sites das Instituições de Educação Superior (IES) pesquisadas -, com recorte temporal dos anos de 2015 e 2016.

A pesquisa, embora defina como seu lócus espacial a Mesorregião Leste ${ }^{\text {ii }}$ do Estado de Mato Grosso do Sul, não objetivou o levantamento em todos os 18 municípios que compõem a região, mas foca num conjunto de 10 municípios que recebem influência direta da atuação da Universidade Federal de Mato Grosso do Sul (UFMS), Campus de Três Lagoas (CPTL).

Os municípios de Três Lagoas, Água Clara, Cassilândia, Inocência, Paranaíba, Santa Rita do Pardo, Selvíria, Brasilândia, Aparecida do Taboado e Bataguassu em seu conjunto respondem por uma área territorial de aproximadamente 50.000 .000 de $\mathrm{Km}^{2}$ e por uma população de 255.000 habitantes, com uma densidade demográfica média de 3 habitantes por $\mathrm{Km}^{2}$, conforme dados do Instituto Brasileiro de Geografia e Estatística (IBGE) de 2010. Municípios que em seu conjunto caracterizam a região de fronteira entre o Estado de Mato Grosso do Sul com os Estados de São Paulo, Minas Gerais e Goiás.

$\mathrm{O}$ artigo discute, inicialmente, as características atuais da influência internacional para a educação superior, posteriormente, indica o alinhamento da legislação educacional brasileira em face da referida influência. Por fim, busca elucidar as implicações para a política de formação de professores, especificamente, para a formação em Pedagogia.

\section{A CONSTRUÇÃO de CONSENSOS INTERnACIONAIS PARA A EDUCAÇÃO SUPERIOR}

A especulação socioeconômica, cultural e política em torno à aproximação ao século XXI caracteriza a última década do século XX, especialmente para a educação, como lócus/tempo que congrega as expectativas por profundas mudanças. Expectativa capaz de disparar movimentos internacionais na busca de consensos para a mudança e transformação da educação face às demandas produtivas, sociais e culturais do novo século.

A Organização das Nações Unidas para a Educação, a Ciência e a Cultura (UNESCO), com olhar específico para a educação superior, consequentemente, naquilo que objetiva a presente pesquisa, para a política e pedagogia de formação de professores com habilidades e competências adequadas ao novo século, candidata-se como agente supraestatal, suprapartidário e supraideológico, para o fomento e orientação das mudanças e transformações necessárias.

\begin{tabular}{l|c|c|c|c|c|c|}
\hline (C) Rev. Educ. Perspec. & Viçosa, $M G$ & v.9 & n.2 & p.313-329 & maio/ago. 2018 & eISSN 2178-8359 \\
\hline
\end{tabular}


A proposta da UNESCO parece objetivar a mediação de um disciplinamento dos sistemas educacionais locais a um suposto pacto articulado por uma racionalidade de consenso global. Dessa forma, é possível identificar como passo inicial a socialização do documento lançado em 1995, reproduzido no Brasil em 1999, sob o título de "Política de Mudança e Desenvolvimento no Ensino Superior", centrado na descrição das tendências mundiais do ensino superior em tempos de constantes transformações.

A natureza descritiva do documento parece não superar uma leitura normativa e adaptativa da educação superior responsabilizando-a pelo desenvolvimento social sustentável mediante a promoção da atual matriz desenvolvimentista e econômica. Assim, as propostas de educação superior que melhor se adaptam à referida matriz figuram, também, como políticas orientadas para os países signatários do pacto articulado pela UNESCO, reforçando o fomento às políticas como diversificação e flexibilidade institucional, aprofundamento da lógica do ensino, construção de parceria empresarial, abertura para a incidência externa (internacionalização) e o fomento à criação de plataformas para ensino virtual (UNESCO, 1999).

Esse disciplinamento proposto pela UNESCO, após e concomitante à socialização do referido documento, dá vazão a uma série de Conferências Regionais que convergem para a Conferência Mundial de Educação Superior de 1998, em Paris, conferindo materialidade oficial ao pacto com a "Declaração Mundial sobre Educação Superior no Século XXI: visão e ação”. A declaração parece reafirmar os princípios já indicados no documento supracitado, destacando como função da educação superior o treinamento com base em habilidades focado no mérito individual, igualdade de oportunidades pela diversificação institucional, proposta metodológica focada na aprendizagem, gestão institucional e revisão curricular parceirizadas com os agentes empregadores e a reafirmação do fomento à criação de plataformas para ensino virtual (UNESCO, 1998).

A referida Declaração Mundial indica o impacto sobre o próprio conceito de universidade, consequentemente, da pedagogia universitária, diluindo-a no conceito de ensino superior, reclamado a partir de expressões flexíveis e diversificadas. "A organização procura promover a diversidade entre as instituições e sistemas de ensino superior" (UNESCO, 1999, p. 19), possibilitando a afirmativa de que "um dos resultados diretos tem sido a diversificação do ensino superior em praticamente todas as regiões do mundo" (UNESCO, 1999, p. 33). Disciplinamento que compactua com a definição de que

a educação superior compreende todo tipo de estudos, treinamento ou formação para a pesquisa em nível pós-secundário, oferecidos por universidades ou outros estabelecimentos educacionais aprovados como instituições de educação superior pelas autoridades competentes do estado (UNESCO, 1998, p. 1). 
Dias Sobrinho (2010), aponta para a intencionalidade político-pedagógica desta abordagem que restringe a universidade à flexível definição de ensino superior ou a ainda mais imprecisa e abrangente definição de educação pós-secundária, possibilitando outro indicativo decorrente desta proposta reformista no que se refere à adoção das plataformas virtuais, indicando para o desenvolvimento progressivo da modalidade do ensino a distância, prevendo que todas as universidades deveriam ser "abertas" oferecendo a possibilidade de aprender a distância (UNESCO, 1999). A Declaração prevê, inclusive, a criação de "novos ambientes de aprendizagem, que vão desde os serviços de educação a distância até as instituições e sistemas de educação superior totalmente virtuais" (UNESCO, 1998, p. 12).

Esses disciplinamentos parecem convergir para a própria reavaliação da missão das instituições universitárias, devendo aprofundar os elos "com organizações, comércio e indústria" (UNESCO, 1999, p. 61). A referência para a ideia de qualidade educacional, tanto da gestão institucional, quanto da gestão curricular, está condicionada à adoção das orientações e modelos provenientes da experiência do mundo corporativo. A proposta prevê, inclusive, a ocupação das cadeiras de gestão e docência pelos agentes corporativos, tornando "mais fácil, aos especialistas de setores econômicos e outros ensinar em instituições de ensino superior [...] dessa forma, injetar novas ideias e programas de estudo" (UNESCO, 1999, p. 62), proposta complementada pela Declaração ao afirmar da necessidade de fortalecimento dos "vínculos com o mundo do trabalho, por meio da participação de seus representantes nos órgãos que dirigem as instituições [...] e da revisão curricular visando uma aproximação maior com as práticas de trabalho (UNESCO, 1998, p. 8).

A Universidade do século XXI, na proposta articulada pela UNESCO, tem que assumir um novo pragmatismo político-epistemológico capaz de inserção socioeconômica proativa, materializada a partir de uma nova promessa acadêmica, centrada na aprendizagem, com base no treinamento de alta qualidade, para o desenvolvimento de competências e habilidades para o desenvolvimento econômico, consequentemente, também o social.

A aludida universidade proativa e a nova promessa acadêmica demanda um novo professor, cuja formação está respaldada na missão e função da própria educação superior: "contribuir para o desenvolvimento e melhoria da educação em todos os níveis, em especial por meio da capacitação de pessoal docente" (UNESCO, 1998, p. 2). Bem como, prevê que as instituições de educação superior devem estabelecer orientações claras quanto à "preparação de professores nos níveis pré-escolar, primário e secundário, incentivando a inovação constante nos planos curriculares, as práticas mais adequadas nos métodos pedagógicos e a familiaridade com os diversos estilos de aprendizagem" (UNESCO, 1998, p. 5). 


\section{A LEGISLAÇÃO BRASILEIRA E A LÓGICA DO CONSENSO}

O interesse brasileiro em alinhar seu sistema educacional aos ordenamentos externos não responde como posicionamento novo. Desde a década de 1950, que o Brasil consente com esta política de intervenção justificada como condição para o alcance da modernização nacional (SILVA, 2002).

Os primeiros contornos oficiais desta política podem ser representados pelos denominados acordos de colaboração cultural ou técnica entre o Governo Brasileiro e a United States Agency for International Development (USAID) - Acordo MEC/USAID de 1965 e 1967 objetivando o assessoramento técnico norte-americano para reforma do ensino superior brasileiro, que resultou na chamada reforma disciplinar e modernizadora da universidade, formalizada na Lei 5.540 de 28 de novembro de 1968 (BRASIL, 1968; FAVERO, 1991).

O empenho do governo na construção da política de abertura nacional para os acordos foi compensada mediante volumosos empréstimos capitaneados pelo Fundo Monetário Internacional e pela Agência Norte-Americana para o Desenvolvimento Internacional. Agentes financeiros que foram responsáveis pela intervenção técnica das décadas de 1970 a 1990, promovendo a reforma do endividado estado brasileiro que passa a pactuar com as matrizes político-econômicas derivadas do Consenso de Washington, centradas em políticas de ajuste fiscal e reformas estruturais voltadas para o mercado global (BRESSER-PEREIRA, 1996; SILVA, 2002).

O consentimento para que os organismos financeiros desenhem a proposta de reformas estruturais do estado brasileiro, articulado às políticas de ajuste fiscal, não deixa de afetar profundamente o sistema de educação superior brasileiro, em especial, a universidade pública, que se vê orientada por princípios que a concebe como insumo para o desenvolvimento econômico e social (SILVA, 2002).

Esse disciplinamento está bem representado nas orientações do Banco Mundial que prevê o fomento à diversificação das instituições de ensino, dando ênfase à criação de instituições isoladas, escolas técnicas, cursos de ciclo curto e ensino a distância; diversificação das fontes de financiamento das instituições estatais com a redução do investimento estatal nas instituições públicas; captação de recursos pelas próprias instituições por meio de contratos de prestação de serviço com empresas; redefinição da função do governo no ensino superior diminuindo a preocupação com o aporte financeiro e investindo mais no controle, fiscalização e avaliação; e a preocupação com o repasse de recursos financeiros por critérios de desempenho (SGUISSARDI, 2009). 
O terceiro movimento intervencionista internacional está representado pelo já referido pacto articulado pela UNESCO, anunciando uma proposta de mudança e transformação da educação superior capaz de superar o disciplinamento reformista neoliberal proposto pelo consenso de Washington, que para a própria UNESCO se trata de um modelo que acentuou os índices de pobreza e exclusão social (YARZÁBAL, 2002).

Contudo, conforme já indicado no texto, a proposta da UNESCO, embora aponte como missão fundamental da educação superior o desenvolvimento social sustentável, condiciona esta conquista à sua capacidade de contribuir para a manutenção saudável e para o bom desenvolvimento das matrizes econômicas vigentes - aquelas orientadas pelo Fundo Monetário Internacional - espelhando uma natureza normativa e adaptativa para a educação superior, que não supera as já anunciadas orientações de fomento às políticas de diversificação e flexibilidade institucional; centralidade pedagógica no treinamento para o desenvolvimento de competências e habilidades; gestão institucional e revisão curricular parceirizadas com os agentes empregadores e consolidação de parcerias empresariais; abertura para a incidência externa (internacionalização); e fomento à criação de plataformas para ensino virtual (UNESCO, 1999).

O Brasil, junto a mais de 130 países, é signatário deste ideário reformista que, a partir da Conferência Mundial da Educação Superior de 1988, ganha poder de incidência sobre o Ministério da Educação e de orientação das políticas e reformas educacionais, especialmente, quanto ao financiamento e gestão da educação superior; política de acesso e permanência; implantação de métodos educativos inovadores e avaliação; e políticas de formação de professores (UNESCO, 1998).

Não obstante, a promulgação da Carta Magna da redemocratização de 1988 reconhecendo a finalidade da educação como direito público e de responsabilidade do Estado, conquista reafirmada na Lei de Diretrizes e Bases da Educação Nacional - LDBEN n. 9394 de 1996, é inegável a incidência dos indicados organismos internacionais forçando constantes processos de reforma que para Silva (2002) passam a disciplinar os marcos legais democráticos, racionalizando as formas de transferências de recursos $\left(\mathrm{FUNDEF}^{\mathrm{iii}}\right)$; modalidade decisória $\left(\mathrm{CNE}^{\mathrm{iv}}\right)$; modelos de gestão do sistema $\left(\mathrm{PNE}^{\mathrm{v}}\right)$; matrizes avaliativas (PROVÃO ${ }^{\mathrm{vi}}$ ); e mais recentemente a própria redefinição da caracterização institucional ${ }^{\mathrm{vii}}$ (universidade, centros universitários, institutos superiores, faculdades) e as políticas de formação de professores $\left(\mathrm{UAB}^{\mathrm{viii}}\right)$.

O ordenamento historicamente orientado pelos organismos internacionais, respaldado atualmente nas orientações pactuadas pela UNESCO, materializa-se no sistema educacional brasileiro, pela própria LDB 9394 de 1996, ao salvaguardar no inciso V do artigo $3^{\circ}$, que trata dos princípios e fins da educação brasileira, a "coexistência de instituições públicas e

\begin{tabular}{l|c|c|c|c|c|c|}
\hline (C) Rev. Educ. Perspec. & Viçosa, $M G$ & v.9 & n.2 & p.313-329 & maio/ago. 2018 & eISSN 2178-8359 \\
\hline
\end{tabular}


privadas de ensino", princípio complementado pelo artigo $7^{\circ}$ que indica ser o ensino uma prática livre à iniciativa privada, bastando respeitar as normas gerais da educação nacional, os critérios de autorização de funcionamento e abertura aos processos de avaliação indicados pelo poder público (BRASIL, 1996).

Essa orientação tem especial incidência sobre a organização do ensino superior que no artigo 45, tanto reafirma a natureza público privada das instituições, quanto garante a sua flexibilização prevendo sua oferta "com variados graus de abrangência", chegando a reconhecer, no $\S 2^{\circ}$ do artigo 47 a possibilidade de validar supostos conhecimentos práticos independente da apreciação teórico-metodológica da proposta pedagógica da instituição de ensino superior, conhecimento caracterizado pelo impreciso e flexível conceito "extraordinário aproveitamento nos estudos". Proposição que parece coadunar com a nova proposta de emenda à LDB 9394/96 visando a reforma do Ensino Médio e que permite a ocupação de vagas docentes por pessoas com "notório saber", independente de formação didático-pedagógica para o exercício da profissão docente (BRASIL, 1996).

Essa orientação legal ganha contornos marcantes para a política de formação de professores, já que no artigo 61 da referida LDB 9394/96, que trata da formação de profissionais docentes, reconhece o aproveitamento de experiências em outras atividades e mantém, no artigo 62, a possibilidade de formação de professores, até mesmo, em cursos ofertados em nível médio ${ }^{\mathrm{ix}}$. Posicionamento que afeta de forma direta a organização de instrumentos para a gestão destas políticas como definição de Plano Nacional de Educação (PNE).

O PNE 2001-2010, formalizado na Lei no 010172, de 09 de janeiro de 2001, buscando dar concretude aos princípios orientados pela LDB 9394/96, prospecta de forma categórica a diversificação institucional, estabelecendo, inclusive, como uma das metas "diversificar o sistema superior de ensino, favorecendo e valorizando estabelecimentos não universitários", que para a formação de professores ganha contornos dramáticos uma vez que define como uma das principais políticas a formação na modalidade à distância, iniciando "logo após a aprovação do Plano, a oferta de cursos à distância, em nível superior, especialmente na área de formação de professores para a educação básica" (BRASIL, 2001a).

No contexto educacional brasileiro, a expressão prática deste disciplinamento fica bem caracterizada nas pesquisas e nos números sobre a política de formação de professores. Os dados disponibilizados pelo INEP, utilizando os resultados do Censo da Educação Superior, indicam que em 2010 havia um total de 2.378 Instituições de Ensino Superior, sendo 278 públicas e 2.100 particulares, que em termos de matrícula, ainda segundo o Censo da Educação Superior, considerando as instituições com oferta presencial, aponta para o total de 5.449.120 matrículas, sendo 1.461 .696 em instituições públicas e 3.987.424 em instituições privadas. 
Gatti, Barretto e André (2011) apontam que 60\% dos professores formados no Brasil em 2010 advém de cursos acomodados em instituições isoladas e vinculadas à iniciativa privada, que por sua vez, já acomodava $78 \%$ das vagas ofertadas para formação de professores no Brasil, indicando que até o ano de 2013, especificamente para o curso de pedagogia, a modalidade de educação a distância deveria responder por $85 \%$ das vagas ofertadas.

\section{A PEDAGOGIA UNIVERSitÁRIA PARA FORMAÇÃo DE PEDAGOGOS: IMPACTOS LOCAIS}

A análise dos dados levantados entre os anos de 2015 e 2016, na região Leste de Mato Grosso do Sul, organizados, no âmbito do projeto de pesquisa "Pedagogia Universitária para Formação de Pedagogo e a Qualidade da Educação Básica', com base em dados oficiais MEC, INEP e sites das IES - possibilita a percepção do impacto do referido ordenamento e sua caracterização prática.

A pesquisa indica a atuação de 19 instituições de Ensino Superior com oferta do curso de pedagogia na região. A oferta se estrutura como pública e privada, na modalidade presencial, semipresencial e a distância e pela diversificação institucional a partir de faculdades ${ }^{\mathrm{x}}$, centro universitários e universidades.

A flexibilização e diversificação da oferta já formalizada na legislação educacional brasileira, tanto pelo Decreto n $\mathrm{n}^{\circ}$ 2.306, de agosto de 1997 (BRASIL, 1997) e pelo Decreto $\mathrm{n}^{\circ} 3.860$, de 09 de julho de 2001 (BRASIL, 2011c), quanto pelo Decreto no 5.773, de 09 de maio de 2006, reconhecendo como instituições de ensino superior, à sua organização acadêmica, as universidades, centros universitários e faculdades integradas, faculdades, institutos ou escolas superiores, está bem caracterizada na região, objeto da presente pesquisa.

A análise com base na categoria Tipologia Institucional, que diz do modo de organização institucional e da forma de incidência acadêmica, mostra que das 19 Instituições que ofertam o curso de Pedagogia 12 (63\%) encontram-se credenciadas junto ao MEC como Universidades, 4 (21\%) como Centro Universitário e 3 (16\%) como faculdades, conforme gráfico 1: 


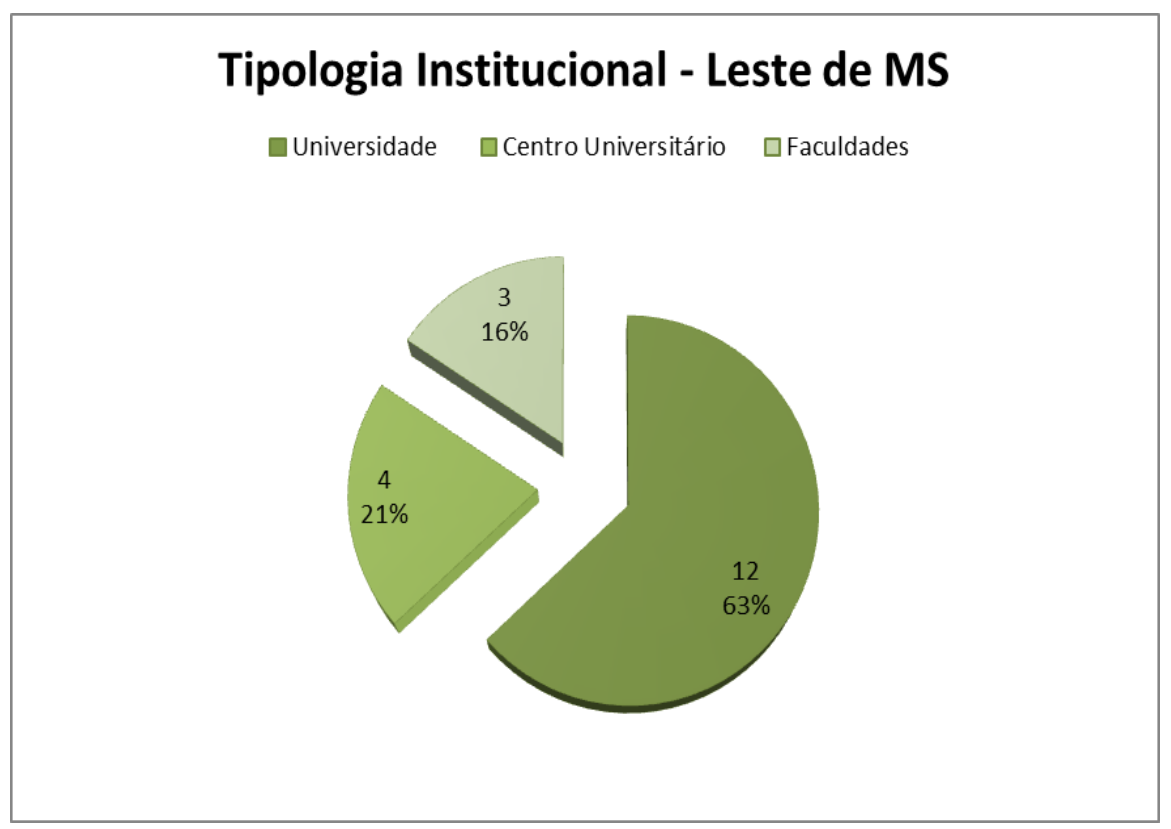

Gráfico 1. Oferta de Curso de Pedagogia por Tipologia Institucional Fonte: Organizado pelo Grupo de Pesquisa

Os dados indicam a opção político epistemológica que demarca a pedagogia de formação dos pedagogos, no contexto da política de expansão do ensino superior na região. A proposta de diversificação institucional, para Scheibe e Aguiar (1999), responde com forte incidência sobre a própria diversificação pedagógica para formação de professores, movimento político intencional, otimizado por meio do caráter generalista e flexível da LDB 9394/96.

Figura oportuno as conclusões de Pinheiro, Castro e Barbalho (2016, p. 302), em pesquisa sobre os cursos de licenciaturas no Brasil.

\footnotetext{
Os dados mostram que as licenciaturas, antes prioridade nas universidades, vêm sendo ofertadas por outros tipos de organização institucional, sobretudo pelos institutos/centros federais, que tradicionalmente tinham como função a formação técnica e profissional para o mercado de trabalho e pelas faculdades que têm uma formação voltada apenas para o ensino. Essa constatação ratifica a intenção do Estado de expandir a educação superior, especialmente a formação de professores, de modo a conter os gastos públicos, para uma formação mais rápida e flexível, apesar do discurso da centralidade da formação do professor.
}

Scheibe e Aguiar (1999), reconhecem que a reboque de ineditismos tipológicos para a educação superior, pulveriza-se a organização acadêmica reconhecendo a educação superior no sistema federal de ensino desde sua expressão universitária até a modalidade de formação técnica pós-média, comumente, estabelecendo como espaço privilegiado para a formação de professores o nível mais baixo desta hierarquia, consequentemente, o menos oneroso. 
Essa diversificação institucional e pedagógico/acadêmica é percebida, também, quando da análise da modalidade de oferta do curso de Pedagogia na região, sendo possível encontrar a oferta presencial, a distância e a semipresencial. Os dados indicam que 69\% da oferta é feita na modalidade de educação a distância, 26\% presencial e 5\% semipresencial (Gráfico 2).

Os números parecem confirmar a lógica, supracitada, de adoção da matriz de redução de custos para a política de formação de pedagogos. Embora o gráfico 1 aponte que 12 instituições, que responde por $63 \%$ da oferta de pedagogia na região, são oficialmente denominadas de instituições universitárias, parecendo indicar uma preocupação com a formação do pedagogo a partir da pedagogia universitária, o gráfico 2 deixa claro que esta oferta está focada em universidades de ensino, uma vez que $69 \%$ da oferta está acomodada na modalidade de educação a distância. Vale destacar que a oferta na modalidade a distância é viabilizada mesmo por instituições públicas federais ${ }^{\mathrm{xi}}$.

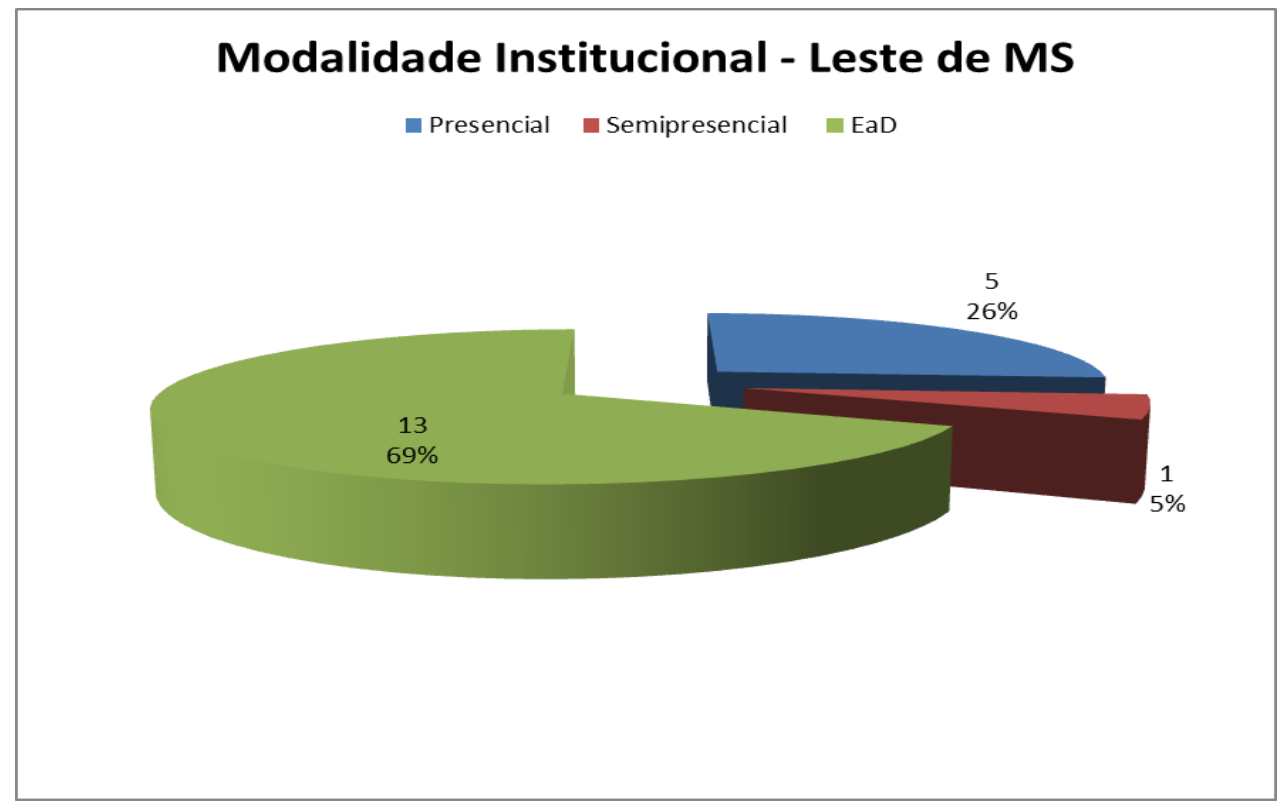

Gráfico 2. Oferta do Curso de Pedagogia por Modalidade Institucional Fonte: Organizado pelo Grupo de Pesquisa

As pesquisas de Giolo (2008) apontam que a política de formação de professores na modalidade de educação a distância, conforme disciplinava o artigo 80 da LDB 9394/96 (BRASIL, 1996), estava acomodada ao domínio das instituições públicas e objetivava promover a formação regular e continuada de professores em exercício. Em 2001, a totalidade das vagas em cursos de Pedagogia e Normal Superior à distância estava em instituições públicas. Iniciativa que está sendo, progressivamente, deslocada do controle e oferta pública para a iniciativa privada ${ }^{x i i}$, que em 2006, já acomodava mais de $70 \%$ das matrículas destes cursos. 
O ano de 2006 marca, inclusive, a própria retomada da participação pública neste modelo de oferta, com a criação do Sistema de Universidade Aberta do Brasil (UAB) pelo Decreto $n^{\circ}$ 5.800 de 08 de junho de 2006 (BRASIL, 2006), que no contexto da política de expansão e interiorização da educação superior se soma a programas de transferência de recursos públicos para ocupação de vagas nas instituições privadas - Programa Universidade para Todos (PROUNI) (BRASIL, 2005) e programas de financiamento público de vagas nas instituições de ensino superior - Fundo de Financiamento Estudantil (FIES) (BRASIL, 2001b), com ênfase na oferta de vagas para cursos de formação de professores para a educação básica, que na prática promove o deslocamento da preocupação com a formação de professores da pedagogia universitária, acomodada nos princípios de qualificada formação técnica, científico pedagógica e política do professor, para uma pedagogia centrada no ensino, em instituições isoladas e amplamente aportada na iniciativa privada.

Essa constatação fica evidente quando são analisados os dados, a partir da categoria Modalidade Jurídico-Administrativa, que trata da natureza pública ou privada das instituições que ofertam o curso de Pedagogia na região. Os dados indicam que expressivos $68 \%$ da oferta é feita por instituições privadas, sendo $32 \%$ em instituições públicas. Lembrando que a maior parte desta oferta pública é realizada na modalidade de educação a distância, conforme gráfico 3:

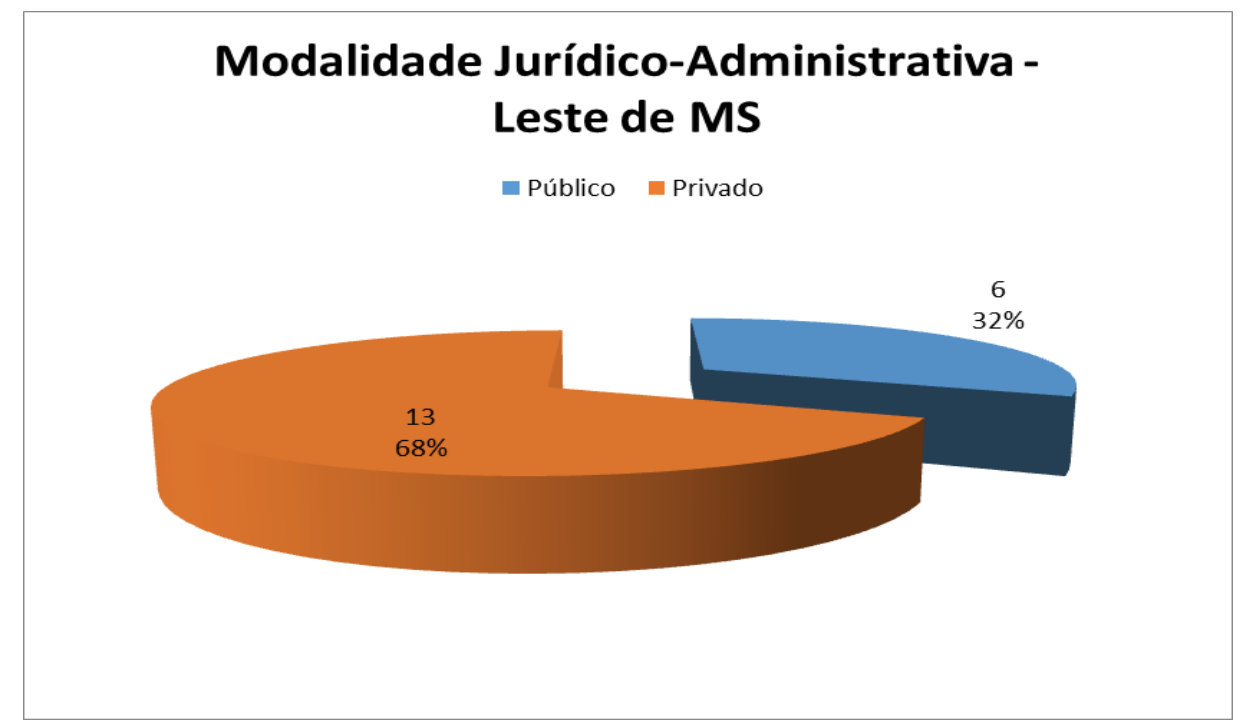

Gráfico 3. Oferta do Curso de Pedagogia por Modalidade Jurídico-Administrativa Fonte: Organizado pelo Grupo de Pesquisa

Pesquisadores como Martins (2009), identificam na reforma universitária de 1968 (BRASIL, 1968) novas características, em termos de natureza e objetivos, na oferta de ensino superior privado no Brasil. 
Trata-se de outro sistema, estruturado nos moldes de empresas educacionais voltadas para a obtenção de lucro econômico e para o rápido atendimento de demandas do mercado educacional. Esse novo padrão, enquanto tendência, subverteu a concepção de ensino superior ancorada na busca da articulação entre ensino e pesquisa, na preservação da autonomia acadêmica do docente, no compromisso com o interesse público, convertendo sua clientela em consumidores educacionais (MARTINS, 2009, p. 17).

O mesmo autor aponta que os responsáveis pelas políticas educacionais na década de 1990, articulados com os diagnósticos e orientações dos organismos internacionais, especialmente do Fundo Monetário Internacional, apostam na desregulamentação e na retração de gastos governamentais para o ensino superior, o que incentivou a expansão do referido modelo de oferta privada.

Entre 1995 e 2002, as matrículas saltaram de 1,7 milhões para 3,5 milhões de estudantes, um crescimento da ordem de $209 \%$. Se o ensino público experimentou um aumento em termos de matrículas, foi o setor privado que comandou essa expansão, uma vez que suas matriculas de graduação cresceram de $60 \%$ para $70 \%$. O número de universidades públicas ficou praticamente estagnado, ao contrário das universidades privadas (MARTINS, 2009, p. 25).

A referida caracterização, para Chaves (2010), está aportada na própria proposta de reforma do estado brasileiro, iniciada na década de 1990, que exige um sistema de ensino mais diversificado e flexível. Política que provoca uma retração do investimento nas instituições públicas e promove a expansão privada da oferta de ensino superior.

Esse modelo de expansão privada da oferta ganha, no atual contexto brasileiro, contornos mercantis claros pela criação de oligopólios, através da fusão de instituições e pela abertura de capitais destas na bolsa de valores.

Desde 2007, o processo de mercantilização do ensino superior brasileiro vem adquirindo novos contornos. Observa-se um forte movimento de compra e venda de IES no setor privado. Além das fusões, que têm formado gigantes da educação, as "empresas de ensino" agora abrem o capital na bolsa de valores, com promessa de expansão ainda mais intensa e incontrolável. [...] É importante ressaltar que grande parte do capital dessas empresas é oriunda de grupos estrangeiros, em especial, de bancos de investimentos norte-americanos, que encontram, nesse setor, um mercado muito favorável ao aumento de seus lucros (CHAVES, 2010, p. 491).

As instituições que trabalham com a formação de professores, consequentemente, com a formação do pedagogo, estão diretamente implicadas com a referida política de expansão da oferta. Os dados supracitados evidenciam que a caracterização da oferta dos cursos de Pedagogia na região Leste do Estado de Mato Grosso do Sul está profundamente marcada por esse disciplinamento.

A leitura dos dados possibilita a percepção da opção política da expansão e interiorização da educação superior pelo fomento da oferta privada, que entendemos como privatização por

\begin{tabular}{l|c|c|c|c|c|c|}
\hline (C) Rev. Educ. Perspec. & Viçosa, $M G$ & v.9 & n.2 & p.313-329 & maio/ago. 2018 & eISSN 2178-8359 \\
\hline
\end{tabular}


meio da expansão da oferta de cursos nesta modalidade institucional, e deslocada da pedagogia universitária, com especial incidência para a política de formação de professores em condições que privilegiam o ensino, já que não estão estudando em instituições universitárias.

\section{CONSIDERAÇÕES FINAIS}

O trabalho destaca a dificuldade do sistema educacional brasileiro em garantir a formação de pedagogos, no âmbito da pedagogia universitária. Prevaleceu, historicamente, a formação secundarista, Cursos Normais, para a formação dos professores da educação primária, formação deslocada do contexto da formação superior.

O debate em torno à LDB 9394/96, embora indique pela formação do pedagogo a partir da pedagogia universitária, já traz as marcas das orientações propostas pelos organismos internacionais, que força a regulamentação desta pedagogia por meio da política de diversificação institucional e acadêmica.

Os dados analisados, com base na oferta de Cursos de Pedagogia na Mesorregião Leste do Estado do Mato Grosso do Sul, caracterizam o referido ordenamento pelo aprofundamento das propostas de formação aportadas em matrizes de redução de custos, materializada no fomento da oferta via instituições privadas, com absoluta predominância da modalidade de educação a distância e no escopo da diversificação institucional vinculada à pedagogia do ensino.

Esses apontamentos, tanto indicam para o modelo, fortemente assentado na iniciativa privada, de expansão e interiorização da educação superior, quanto reclamam o aprofundamento das pesquisas, não apenas pelo viés da regulamentação da expansão da oferta, mas também pela própria possibilidade de incidência sobre a política de expansão a partir de indicadores que caracterizem a preocupação com a qualidade científico-cultural da formação dos pedagogos enquanto compromisso político e epistemológico para com a qualidade da Educação Básica.

\section{REFERÊNCIAS}

BRASIL. Lei $\mathbf{n}^{0}$ 5.540, de 28 de novembro de 1968. Fixa normas de organização e funcionamento do ensino superior e sua articulação com a escola média, e dá outras providências. Brasília, 1968.

BRASIL. Constituição Federal de 1988. Constituição da República Federativa do Brasil. Brasília. Senado Federal, 1988.

\begin{tabular}{l|l|l|l|l|l|l} 
(C) Rev. Educ. Perspec. & Viçosa, $M G$ & v.9 & n.2 & p.313-329 & maio/ago. 2018 & eISSN 2178-8359 \\
\hline
\end{tabular}


BRASIL. Ministério da Educação. Lei no 9.394/1996. Diretrizes e Bases da Educação Nacional. Brasília, 1996.

BRASIL. Decreto no 2.306, de 19 de agosto de 1997. Regulamenta, para o Sistema Federal de Ensino, as disposições contidas no art. 10 da Medida Provisória ${ }^{\circ}$ 1.477-39 de 8 de agosto de 1997 , e nos arts. 16, 19, 20, 45, 46 e $\S 1^{\circ}, 52$, parágrafo único, 54 e 88 da Lei no 9.394, de 20 de dezembro de 1996, e dá outras providências. Brasília, 1997.

BRASIL. Lei no 010172, de 09 de janeiro de 2001. Aprova o Plano Nacional de Educação e dá outras providências. Brasília, 2001a.

BRASIL. Lei $\mathbf{n}^{\mathbf{0}} \mathbf{1 0 . 2 6 0}$, de 12 de julho de 2001. Dispõe sobre o Fundo de Financiamento ao estudante do Ensino Superior e dá outras providências. Brasília, 2001 b.

BRASIL. Decreto n⿳ 3.860, de 9 de julho de 2001. Dispõe sobre a organização do ensino superior, a avaliação de cursos e instituições, e dá outras providências. Brasília, 2001c.

BRASIL. Lei no 11.096, de 13 de janeiro de 2005. Institui o Programa Universidade para Todos - PROUNI, regula a atuação de entidades beneficente de assistência social no ensino superior; altera a Lei n ${ }^{\circ} 10.891$, de 9 de julho de 2004, e dá outras providências. Brasília, 2005.

BRASIL. Decreto $\mathbf{n}^{\circ}$ 5.800, de 08 de junho de 2006. Dispõe sobre o Sistema Universidade Aberta do Brasil - UAB. Brasília, 2006.

BRESSER-PEREIRA, Luiz Carlos. Crise Econômica e Reforma do Estado no Brasil: para uma nova interpretação da América latina. São Paulo: Editora 34, 1996.

CHAVES, Vera Lúcia Jacob. Expansão da Privatização/Mercantilização do Ensino Superior Brasileiro: a formação dos oligopólios. Educação e Sociedade, Campinas, v. 31, n. 11, p. 481-500, abr./jun. 2010.

DIAS SOBRINHO, José. Dilemas da Educação Superior no Mundo Globalizado: sociedade do conhecimento ou economia do Conhecimento? São Paulo: Casa do Psicólogo, 2010.

FAVERO, Maria de Lurdes de Albuquerque. Da Universidade "Modernizada" à Universidade Disciplinada: Atcon e Meira Mattos. São Paulo: Cortez: Autores Associados, 1991.

GATTI, Bernardete Angelina; BARRETTO, Elba Siqueira de Sá; ANDRÉ, Marli Eliza Dalmazo de Afonso. Política Docente no Brasil: um estado da arte. Brasília: UNESCO, 2011. 
GIOLO, Jaime. A Educação a Distância e a Formação de Professores. Educação \& Sociedade, Campinas, v. 29, n. 105, p. 1211-1234, set./dez. 2008.

MARTINS, Carlos Benedito. A reforma universitária de 1968 e a abertura para o ensino superior privado no Brasil. Educação \&. Sociedade, Campinas, v. 30, n. 106, p. 15-35, jan./abr. 2009.

PINHEIRO, Maria Paula de Melo Pereira; CASTRO, Alda Maria Duarte Araújo;

BARBALHO, Maria Goretti Cabral. Expansão e Diversificação dos Cursos de Licenciatura no Brasil (2003-2010). Anais do XXIV Seminário Nacional UNIVERSITAS/BR. Universidade Estadual de Maringá, p. 295-306, 2016.

SCHEIBE, Leda; AGUIAR, Márcia Angela. Formação de Profissionais da Educação no Brasil: o curso de pedagogia em questão. Educação \& Sociedade, Campinas, ano XX, n. 68, p. 220-238, dez. 1999.

SGUISSARDI, Valdemar. Universidade Brasileira no Século XXI: desafios do presente. São Paulo: Cortez, 2009.

SILVA, Maria Abadia da. Intervenção e Consentimento: a política educacional do Banco Mundial. Campinas: Autores Associados: São Paulo: FAPESP, 2002.

UNESCO. Declaração Mundial sobre a Educação Superior no Século XXI: visão e ação. UNESCO, 1998.

UNESCO. Política de Mudança e Desenvolvimento no Ensino Superior. Tradução e revisão Laura A. Ferrantini Fusaro. Rio de Janeiro. Garamond, 1999. 100p.

YARZÁBAL, Luis. Consenso para a Mudança na Educação Superior. Curitiba: Champagnat, 2002.

\section{NOTAS}

\footnotetext{
${ }^{\text {i }}$ Projeto denominado de "Pedagogia Universitária para Formação de Pedagogos e a Qualidade da Educação Básica”, vinculado à Universidade Federal de Mato Grosso do Sul (UFMS), Campus Três Lagoas (CPTL) e aportado junto ao Grupo de Pesquisa Laboratório Multidisciplinar de Ensino e Aprendizagem (LEA). Cadastrado no Diretório de Grupos do CNPq e certificado pela UFMS.

ii A Mesorregião Leste do Estado de Mato Grosso do Sul é a reunião de duas microrregiões, a saber: Microrregião de Paranaíba (mais ao norte), Microrregião de Três Lagoas (ao centro) e Microrregião de Nova Andradina (mais ao sul).

iii Lei n 9.424 de 24 de dezembro de 1996, que dispõe sobre o Fundo de Manutenção e desenvolvimento do Ensino Fundamental e de Valorização do Magistério (FUNDEF). Que será substituído pelo Fundo de Manutenção e Desenvolvimento da Educação Básica e de Valorização dos Profissionais da Educação (FUNDEB), Lei n ${ }^{\circ} 11.494$ de 20 de junho de 2007.

iv Lei no 9.131, de 24 de novembro de 1995, que trata da constituição e disciplinamento das funções no Conselho Nacional de educação.
}

\begin{tabular}{l|l|l|l|l|l|l} 
(C) Rev. Educ. Perspec. & Viçosa, $M G$ & v.9 & n.2 & p.313-329 & maio/ago. 2018 & eISSN 2178-8359 \\
\hline
\end{tabular}


${ }^{\mathrm{v}}$ Lei no 010.172 , de 09 de janeiro de 2001, que aprova o Plano Nacional de Educação e dá outras providências.

${ }^{\text {vi }}$ Criado pela Lei $n^{\circ}$ 9.131, de 24 de novembro de 1995 e regulamentado pela Portaria ${ }^{\circ} 249$, de 18 de março de 1996.

vii Decreto $n^{\circ} 3.860$, de 09 de julho de 2001, que dispõe sobre a organização do ensino superior, a avaliação de cursos e instituições de ensino superior e dá outras providências.

viii Decreto n 5.800 de 08 de junho de 2006, que dispõe sobre o Sistema de Universidade Aberta do Brasil.

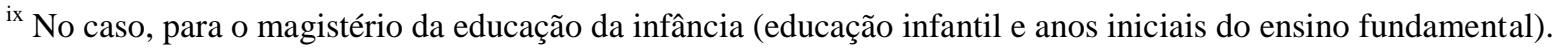

${ }^{x}$ Não obstante o disciplinamento legal das IES, no contexto da legislação educacional brasileira, que prevê uma distinção entre Faculdades Integradas e/ou Isoladas, a presente pesquisa, tendo como foco a pedagogia de formação de professores considera inexpressiva, metodologicamente, a referida distinção, uma vez que ambas tem como exigência legal uma pedagogia centrada, meramente, no ensino, sem exigências quanto à extensão e à pesquisa. Assim, usa-se, aqui, a categoria Faculdade indicando tanto as Faculdades Integradas quanto as Isoladas.

xi A Universidade Federal de Mato Grosso do Sul (UFMS) e a Universidade Federal da Grande dourados (UFGD), atendem cidades da região com ofertas do curso de pedagogia a partir de suas plataformas de educação a distância.

xii Este deslocamento é legalmente amparado no sistema educacional brasileiro pela Lei ${ }^{\circ} 010172$ de 2001 , Decreto $n^{\circ} 5.622 / 2005$ e Decreto $n^{\circ} 6.303$ de 2007.

\section{Sobre os Autores}

${ }^{1}$ Paulo Fioravante Giareta - Doutorado em Educação pela UFPR. Professor da Universidade Federal de Mato Grosso do Sul. E-mail: pfgiareta27@yahoo.com.br - ORCID: https://orcid.org/0000-0002$\underline{0649-4756}$

${ }^{2}$ Valdeci Luiz Fontoura dos Santos - Mestre em Educação pela Universidade Estadual Paulista. Professor Assistente da Universidade Federal de Mato Grosso do Sul - E-mail: valdeci.fontoura@ufms.br-ORCID: https://orcid.org/0000-0002-7405-8251

${ }^{3}$ Juliana Bernardi Petek - Mestre em Educação pela Universidade Estadual de Mato Grosso do Sul. E-mail: juh_petek@hotmail.com - ORCID: https://orcid.org/0000-0002-7299-6789 